Çukurova Üniversitesi Mühendislik Mimarlık Fakültesi Dergisi, 29(1), ss. 145-155, Haziran 2014

Cukurova University Journal of the Faculty of Engineering and Architecture, 29(1), pp. 145-155, June 2014

\title{
Yavaş Değişen Kritik-Altı Açık Kanal Akımının k-e Türbülans Kapatma Modelleri ile Sayısal Hesabı
}

\author{
M. Ali İSPİR ${ }^{1}$, M. Salih KIRKGÖZ ${ }^{* 1}$, Veysel GÜMÜŞ ${ }^{1}$ \\ ${ }^{l}$ Ç.Ü., Mühendislik-Mimarlık Fakültesi, İnşaat Mühendisliği Bölümü, Adana
}

\section{Özet}

Yavaş değişen kritik-altı açık kanal akımının (M1 profili) hız alanı, Lazer Doppler Anemometresi (LDA) ile ölçülmüş ve aynı deney koşullarındaki akımlar için, temel denklemler, sonlu hacimler yöntemine dayalı ANSYS-Fluent paket programı ile çözülmüştür. Sayısal hesaplamalarda, Standard k- $\varepsilon$,

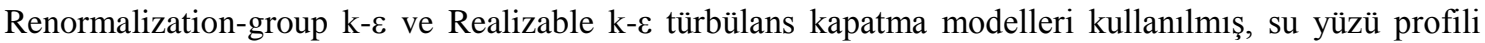
VOF yöntemi ile hesaplanmıştır. Sayısal modellerden elde edilen akım hızları deneysel ölçümlerle karşılaştırılmıştır. Farklı türbülans modellerinin deneysel olarak doğrulanması amacıyla yapılan karşılaştırmalarda, Realizable k- $\varepsilon$ türbülans modelinin, hız alanının hesaplanmasında, kullanılan üç model arasında en başarılı olduğu görülmüştür.

Anahtar Kelimeler: Açık kanal akımı, Hız profili, Sayısal hesaplama, VOF, Türbülans kapatma modelleri

\section{Numerical Analysis of Gradually Varied Subcritical Open Channel Flow Using k- $\varepsilon$ Turbulence Closure Models}

\begin{abstract}
The velocity field of gradually varied subcritical open channel flow (M1 profile) is measured using Laser Doppler Anemometry (LDA). Basic equations of the problem are solved by ANSYS-Fluent program package, using finite volume method, for the flow case having the same experimental conditions. In the numerical simulations, Standard k- $\varepsilon$, Renormalization-group k- $\varepsilon$ and Realizable k- $\varepsilon$ turbulence closure models are used, and the flow profile is computed using VOF method. Computational results for velocities are compared with measured data. Experimental validations of the turbulence models show that, Realizable k- $\varepsilon$ turbulence model, among the three, is in general the most successful one in predicting the velocity field of the present flow case.
\end{abstract}

Keywords: Open channel flow, Velocity profile, Numerical analysis, VOF, Turbulence closure models

\footnotetext{
* Yazışmaların yapılacağı yazar: M. Salih KIRKGÖZ, Ç.Ü. Mühendislik-Mimarlık Fakültesi, Inşaat Mühendisliği Bölümü, Adana.skirkgoz@cukurova.edu.tr
} 


\section{GíRiş}

Su akımı ile etkileşimde bulunan mühendislik yapılarının analiz ve tasarımında iki temel yaklaşımın bulgularından yararlanılmaktadır. Bunlar, deneysel çalışmalardan edinilen bilgi ve bulguların yanı sira, sayısal hesaplama yöntemlerinin kullanıldığı teorik modellemelere dayanmaktadır. Daha hızlı ve ekonomik olması nedenleriyle, su-yap1 etkileşim problemlerinin sayısal yöntemlerle analizi günümüzde giderek daha fazla uygulama alanı bulmaktadır.

Hesaplamalı Akışkanlar Dinamiği (HAD) yöntemleri ile akımı idare eden temel denklemlerin sayısal çözümü yapılarak, akımın serbest yüzeyi ile hız ve gerilme alanları ayrıntılı bir şekilde hesaplanabilmektedir. Türbülanslı akımların HAD yöntemleriyle sayısal olarak hesaplanmasında hareket denklemlerinin çözülebilmesi için gerekli olan ve son yıllarda geliştirilme çabaları yoğunlaştırılmış olan türbülans kapatma modelleri önemli bir yer tutmaktadır. Sayısal hesaplamada kullanılan bir türbülans kapatma modelinin başarısı, problemin çözümündeki başarı düzeyini doğrudan etkilemektedir. Sayısal hesaplamalardan elde edilen teorik bulguların doğrulanması, problemin fiziksel model bulguları ile karşılaştırılması suretiyle yapılabilmektedir. Son yıllarda, çeşitli etkileşim problemlerinin araştırılması kapsamında, sayısal hesaplamaların deneylerle doğrulanmasına yönelik çalışmalarda önemli artışlar sağlanmıştır.

Su yapıları ile etkileşim halindeki türbülanslı akımların analizinde ihtiyaç duyulan türbülans kapatma modelleri ile birlikte, su yüzü profillerinin hesabında Akışkan Hacimleri (Volume of FluidVOF) yöntemi başarı ile kullanılmaktadır [1-8]. HAD uygulamalarında kullanılan türbülans modellerinin güvenilirliğini artırmak bakımından, türbülanslı akımların VOF yöntemine dayalı sayısal çözümlerinin deneylerle doğrulanmasına yönelik çalışmaların çeşitlendirilmesi ve çoğaltılmasına ihtiyaç vardır. Mevcut çalışma bu amaç doğrultusunda gerçekleştirilmiştir.

Çalışmada, dikdörtgen kesitli kanalda yavaş değişen üniform-olmayan kritik-altı akımın farklı kesitlerdeki hızları Lazer Doppler Anemometresi (LDA) ile ölçülmüştür. Deney akımları sonlu hacimler yöntemine dayalı ANSYS-Fluent paket programı kullanılarak sayısal olarak modellenmiş ve çözümü yapılmıştır. Türbülanslı akımın sayısal çözümünde, $k-\varepsilon$ modelleri grubunda yer alan Standart $k-\varepsilon$, Renormalization Group $k-\varepsilon$ ve Realizable $k$ - $\varepsilon$ türbülans modelleri kullanılmıştır. Kullanılan hesaplama ağ yapısının sayısal çözümler üzerindeki etkisini araştırmak için GCI (Grid Convergence Index) yöntemi kullanılmıştır.

Sayısal hesaplamalardan elde edilen çeşitli kesitlerdeki akım hız profilleri, deneysel ölçümlerle karşılaştırılmış ve kullanılan türbülans modellerinin hız profillerinin tahminindeki başarısı tartışılmıştır.

\section{MATERYAL VE YÖNTEM}

\subsection{Deneyler}

Deneyler, uzunluğu 2,4 m, genişliği $0,2 \mathrm{~m}$ ve derinliği 0,2 m olan, tabanı da cam kaplamalı bir laboratuvar kanalında yavaş değişen kritik-altı açık kanal akımı (M1 türü profil) üzerinde yapılmıştır. Şekil 1'de şematik görünümü verilen test düzeneğinde, deneyler iki farklı debi durumu için gerçekleştirilmiş ve deney koşullarını yansıtan, debi $(Q)$ ile kanal başında ölçülen ve hesaplanan su derinliği $\left(h_{\mathrm{o}}\right)$, akım ortalama hızı $\left(V_{\mathrm{o}}\right)$ ve Froude sayısı $\left(F r_{0}\right)$ gibi karakteristik büyüklükler Çizelge 1'de gösterilmiştir.

Akım hızlarının belirlenmesinde Dantec $\AA$ LDA62N04 hız ölçme sistemi kullanılmıştır. LDA sisteminin deney ortamındaki şematik düzeni Şekil 1'de görülmektedir. $\mathrm{Bu}$ sistem, ölçüm bölgesine gönderilen iki lazer 1şınının kesiştiği noktadan geçen parçacıklar yardımıyla, o noktadaki lazer ışınları düzlemindeki anlık akım hız bileşeninin belirli zaman aralıklarında ölçülmesini sağlamaktadır. Zaman serisi olarak kaydedilen hiz değerlerinden, söz konusu noktaya ait zamansal ortalama akım hızı, türbülans hız sapınçları, türbülans şiddeti gibi çeşitli türbülans karakteristiklerinin belirlenmesi mümkün olmaktadır. 
Çizelge 1. Kanaldaki deney koşulları

\begin{tabular}{|l|c|c|c|c|}
\hline & $\boldsymbol{Q}\left(\mathbf{m}^{\mathbf{3}} / \mathbf{s}\right)$ & $\boldsymbol{h}_{\mathbf{0}}(\mathbf{m})$ & $\boldsymbol{V}_{\mathbf{o}}(\mathbf{m} / \mathbf{s})$ & $\boldsymbol{F r}_{\mathbf{0}}$ \\
\hline Deney 1 & 0.00711 & 0.086 & 0.41756 & 0.4546 \\
\hline Deney 2 & 0.00249 & 0.055 & 0.22642 & 0.3082 \\
\hline
\end{tabular}

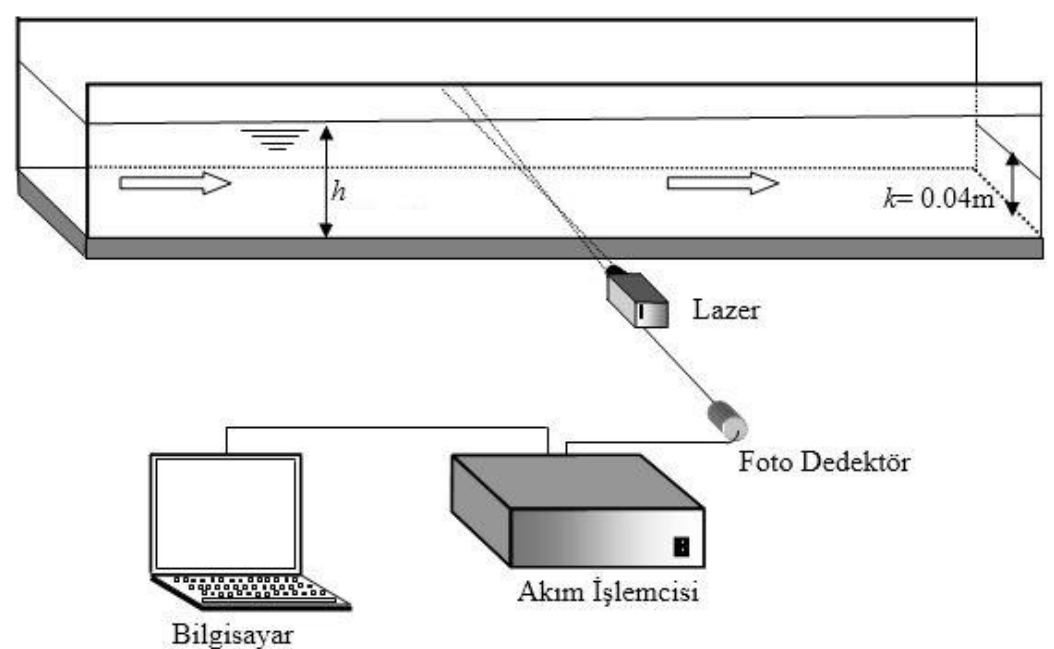

Şekil 1. Deney düzeneği

\subsection{Temel Denklemler}

İncelenen açık kanal akımı düzenli, iki-boyutlu, sıkışmayan, türbülanslı bir serbest yüzeyli akımdır. Akımı idare eden temel denklemler, kütlenin korunumu ve momentumun korunumu (Reynoldsortalamalı Navier-Stokes) denklemleri aşă̆ıdaki gibidir:

$\frac{\partial \bar{u}_{i}}{\partial x_{i}}=0$

$\rho\left(\frac{\partial \bar{u}_{i}}{\partial t}+\bar{u}_{j} \frac{\partial \bar{u}_{i}}{\partial x_{j}}\right)=\rho g_{i}-\frac{\partial \bar{p}}{\partial x_{i}}+\mu \frac{\partial^{2} \bar{u}_{i}}{\partial x_{j}^{2}}+\frac{\partial \tau_{i j}}{\partial x_{j}}$

(1) ve (2) denklemlerinde $u_{i}, x_{i}$ doğrultusundaki hız bileşeni, $g$ yer çekimi ivmesi, $p$ basınç, $\mu$ dinamik viskozite, $\rho$ akışkan yoğunluğu ve $\tau_{i j}$ türbülans (Reynolds) gerilmeleridir. Bu çalışmaya konu olan iki-boyutlu akımı idare eden yukarıdaki 3 adet denklem 6 adet bilinmeyen içermektedir, bunlar: iki hız bileşeni $\bar{u}_{i}$, basınç $\bar{p}$ ve üç bağımsız
Reynolds gerilmesidir $\left(-\rho \overline{u_{i}^{\prime} u_{j}^{\prime}}\right)$. Böylece, denklem sisteminin çözülebilmesi için türbülans gerilmelerinin tanımlanmasına ihtiyaç duyulmaktadır. $\mathrm{Bu}$ sorun, yukarıdaki zamansalortalama denklemlerin sayısal çözümü sürecinde, denklemlerde yer alan türbülans gerilmelerinin uygun türbülans kapatma modelleriyle tanımlanmasını gerektirmektedir. Türbülans viskozitesinin doğrusal olarak ifade edilmesini esas alan Boussinesq yaklaşımına göre (2) denklemindeki türbülans kayma gerilmeleri bünye denklemi ile, sıkışmayan akımlar için aşağıdaki gibi verilmiştir:

$\tau_{i j}=-\rho \overline{u_{i}^{\prime} u_{j}^{\prime}}=\mu_{t}\left(\frac{\partial \bar{u}_{i}}{\partial x_{j}}+\frac{\partial \bar{u}_{j}}{\partial x_{i}}\right)-\frac{2}{3} \rho k \delta_{i j}$

burada $u_{i}^{\prime}$ ve $u_{j}^{\prime}$ yatay ve düşey türbülans hız sapınçları, $\mu_{t}$ türbülans viskozitesi, $k\left(=\overline{u_{i}^{\prime} u_{i}^{\prime}} / 2\right)$ türbülans kinetik enerjisi ve $\delta_{i j}$ Kronecker deltadır. 


\subsection{Türbülans Modelleri}

Denklem (3)'de görülen $\mu_{t}$ türbülans viskozitesinin hesaplanmasında bir çok türbülans kapatma modeli geliştirilmiştir. $\mathrm{Bu}$ çalışmada, $\mu_{t}^{\prime}$ nin hesabında, yaygın bir uygulama alanı olan, $k-\varepsilon$ tabanlı üç türbülans kapatma modeli kullanılmıştır:

- $\quad$ Standard $k-\varepsilon$ (SKE) [9],

- Renormalization Group $k-\varepsilon(\mathrm{RNG})$ [10],

- $\quad$ Realizable $k-\varepsilon(\mathrm{RKE})[11]$

$\mathrm{Bu}$ modeller aşağıda kısaca açıklanmıştır.

\section{SKE Türbülans Modeli}

$\mathrm{Bu}$ model ile türbülans viskozitesi, $\mu_{t}$, türbülans kinetik enerjisi, $k$, ve onun kayıp oranına, $\varepsilon$, bağlı olarak aşağıdaki gibi ifade edilmektedir:

$\mu_{t}=\rho C_{\mu} \frac{k^{2}}{\varepsilon}$

$C_{\mu}$ boyutsuz model sabitidir. (4) denklemindeki $k$ ve $\varepsilon$ değerlerinin bulunması için iki adet kısmi diferansiyel transport denkleminin çözülmesi gerekmektedir, bunlar:

$$
\begin{aligned}
& \frac{\partial(\rho k)}{\partial t}+\bar{u}_{j} \frac{\partial(\rho k)}{\partial x_{j}}= \frac{\partial}{\partial x_{j}}\left[\left(\mu+\frac{\mu_{t}}{\sigma_{k}}\right) \frac{\partial k}{\partial x_{j}}\right] \\
&+\tau_{i j} \frac{\partial \bar{u}_{i}}{\partial x_{j}}-\rho \varepsilon \\
& \frac{\partial(\rho \varepsilon)}{\partial t}+\bar{u}_{j} \frac{\partial(\rho \varepsilon)}{\partial x_{j}}=\frac{\partial}{\partial x_{j}}\left[\left(\mu+\frac{\mu_{t}}{\sigma_{\varepsilon}}\right) \frac{\partial \varepsilon}{\partial x_{j}}\right] \\
&+C_{1 \varepsilon} \frac{\varepsilon}{k} \tau_{i j} \frac{\partial \bar{u}_{i}}{\partial x_{j}}-C_{2 \varepsilon} \rho \frac{\varepsilon^{2}}{k}
\end{aligned}
$$

SKE model sabitleri, $C_{\mu}=0,09, \sigma_{k}=1,0, \sigma_{\varepsilon}=1,3$, $C_{1 \varepsilon}=1,44, C_{2 \varepsilon}=1,92$ değerlerini almaktadır [9].

\section{RNG Türbülans Modeli}

$\mathrm{Bu}$ modelde $k$-denklemi SKE ile aynı olup $\varepsilon$ denklemi aşağıdaki gibi ilave kaynak terimi içermektedir.

$$
\begin{array}{r}
\frac{\partial(\rho \varepsilon)}{\partial t}+\bar{u}_{j} \frac{\partial(\rho \varepsilon)}{\partial x_{j}}=\frac{\partial}{\partial x_{j}}\left[\left(\mu+\frac{\mu_{t}}{\sigma_{\varepsilon}}\right) \frac{\partial \varepsilon}{\partial x_{j}}\right] \\
+C_{1 \varepsilon}^{*} \frac{\varepsilon}{k} \tau_{i j} \frac{\partial \bar{u}_{i}}{\partial x_{j}}-C_{2 \varepsilon} \rho \frac{\varepsilon^{2}}{k}
\end{array}
$$

Model sabitleri aşağıdaki gibi verilmiştir:

$C_{\mu}=0.0845, \quad \sigma_{k}=\sigma_{\varepsilon}=0.7194$,

$C_{1 \varepsilon}^{*}=C_{1 \varepsilon}-\frac{\eta\left(1-\eta / \eta_{0}\right)}{1+\beta \eta^{3}}, \quad C_{2 \varepsilon}=1.68$

$C_{1 \varepsilon}=1.42, \quad \eta=\left(2 S_{i j} S_{i j}\right)^{1 / 2} \frac{k}{\varepsilon}$,

$S_{i j}=\frac{1}{2}\left(\bar{u}_{i, j}+\bar{u}_{j, i}\right), \quad \eta_{0}=4.377, \quad \beta=0.012$

$S_{i j}$ şekil değiştirme hızı tansörüdür. Görüldüğü gibi (7) denklemi akışkan şekil değiştirmesine bağlı $\eta$ parametresini içermektedir. $\mathrm{Bu}$ ilave parametre sayesinde RNG modelinin ivmelenen, şiddetli eğriselliğe maruz, sınır tabakasının ayrıldığı, ikincil akımlar ve durma noktasının mevcut olduğu akımlarda SKE modeline göre daha gerçekçi sonuçlar verdiği iddia edilmiştir [10].

\section{RKE Türbülans Modeli}

Akım alanındaki yüksek şekil değiştirme hızlarının ve sınır tabakası ayrılmasının mevcut olduğu karmaşık akım durumlarında SKE türbülans modeli üzerinde, performans artırıcı olarak RKE modeli adı altında şu iyileştirmeler yapılmıştır: (a) türbülans viskozitesi, $\mu_{t}$, ifadesinde, sabit bir değer yerine değişken $C_{\mu}$ terimi kullanılarak SKE modelindeki katı yüzeye dik şekil değiştirme bileşenlerinin değeri küçültülmüş, ve (b) $\varepsilon$ transport denkleminde yerel şekil değiştirme hızını esas alan farklı bir kaynak terimi kullanılmıştır. Shih ve diğ. [11] $C_{\mu}^{*}$ için aşağıdaki formülü vermişlerdir:

$C_{\mu}^{*}=\frac{1}{A_{o}+A_{s} \frac{U^{*} k}{\varepsilon}}$

Burada, $A_{o}=4, A_{s}=\sqrt{6} \cos \phi$,

$\phi=\frac{1}{3} \arccos (\sqrt{6} W), \quad W=\frac{S_{i j} S_{j k} S_{k i}}{\tilde{S}^{3}}$,

$\tilde{S}=\sqrt{S_{i j} S_{i j}}, U^{*}=\sqrt{S_{i j} S_{i j}+\tilde{\Omega}_{i j} \tilde{\Omega}_{i j}}$, 
$\tilde{\Omega}_{i j}=\Omega_{i j}-2 \varepsilon_{i j k} \omega_{k}^{*}, \quad \Omega_{i j}=\bar{\Omega}_{i j}-\varepsilon_{i j k} \omega_{k}^{*}$,

$\Omega_{i j}=\frac{1}{2}\left(\bar{u}_{i, j}-\bar{u}_{j, i}\right)$

$\bar{\Omega}_{i j}, \omega_{k}^{*}$ açısal hızı ile dönen eksen takımına göre ölçülen ortalama rotasyon hızı tansörüdür.

$\varepsilon$-denklemi aşağıdaki gibi ifade edilmiştir:

$$
\begin{aligned}
\frac{\partial(\rho \varepsilon)}{\partial t}+\bar{u}_{j} \frac{\partial(\rho \varepsilon)}{\partial x_{j}} & =\frac{\partial}{\partial x_{j}}\left[\left(\mu+\frac{\mu_{t}}{\sigma_{\varepsilon}}\right) \frac{\partial \varepsilon}{\partial x_{j}}\right] \\
& +\rho C_{1} S \varepsilon-\rho C_{2} \frac{\varepsilon^{2}}{k+\sqrt{v \varepsilon}}
\end{aligned}
$$

Model sabitleri aşağıdaki gibi önerilmiştir:

$$
\begin{aligned}
& C_{1}=\max \left[0.43, \frac{\eta}{\eta+5}\right], \quad \eta=S \frac{k}{\varepsilon}, \\
& S=\sqrt{S_{i j} S_{i j}}, \quad C_{2}=1.9, \quad \sigma_{k}=1.0, \quad \sigma_{\varepsilon}=1.2
\end{aligned}
$$

RKE modeli de RNG gibi, ivmelenen, eğrisel, sınır tabakasının ayrıldığı, ikincil akımların var olduğu akımlarda SKE modeline göre daha başarılı olduğu ifade edilmiştir [11].

\subsection{Akışkan Hacimleri Yöntemi (VOF)}

Bu çalışmada, su-hava ara yüzünün hesabında akışkan hacimleri (Volume of Fluid-VOF) yöntemi kullanılmıştır [12]. VOF yöntemi, esas olarak hesaplama ağındaki eleman hacimlerinin boş, kısmen dolu ya da tamamen su ile dolu olduğunu belirlemektedir. A $\breve{g}$ elemanlarının hacimsel doluluk oranını temsilen, $F=1$ için ağ elemanı tam dolu, $F=0$ için boş (hava ile dolu) ve $0>F>1$ için su ile kısmen dolu olmaktadır (Şekil 2)

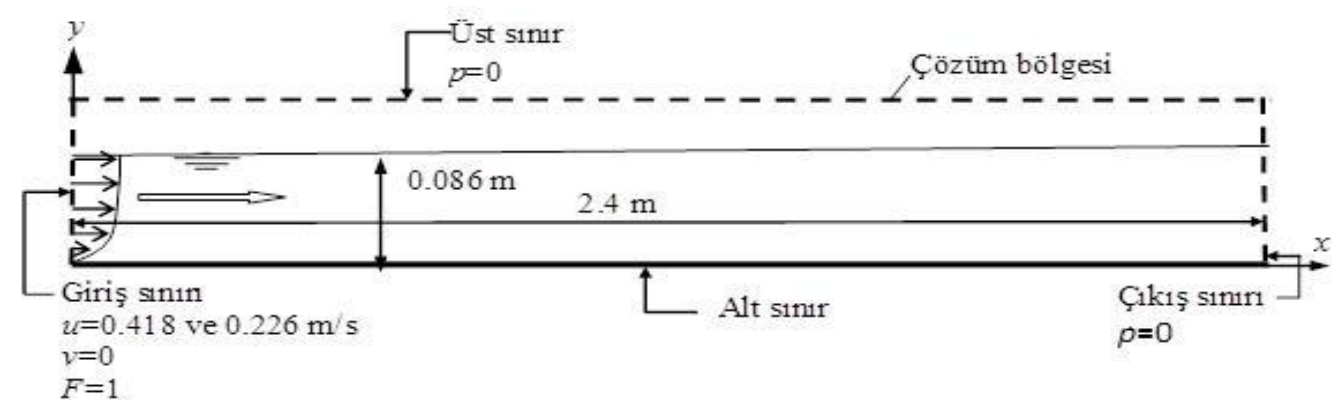

Şekil 3. Sayısal çözüm bölgesi ve sınır şartları

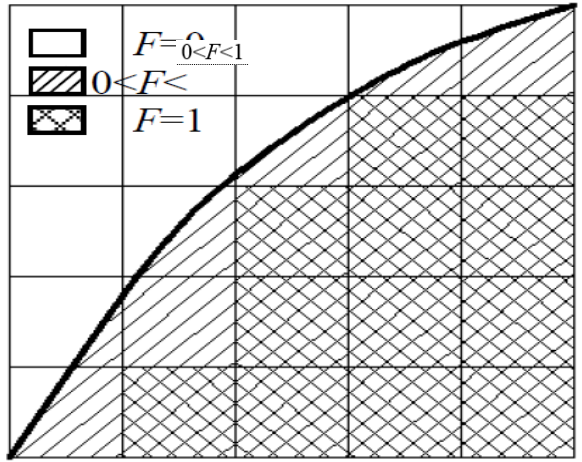

Şekil 2. A $\breve{g}$ elemanlarının doluluk oranı

Bu yaklaşıma göre, öncelikle, kısmen dolu her bir hücrenin, doluluk oranı ve onun türevleri ile ilgili bilgilere dayanılarak, hava-su doğrusal ara yüzünün hücre ağırlık merkezine göre yeri belirlenir. Bir sonraki adımda, hesaplanmış doğrusal ara yüzün yeri ve eleman yüzeylerinde hesaplanmış normal ve teğetsel hız bilgileri kullanılarak her bir eleman yüzeyinden taşınan akışkan miktarları hesaplanır. Son olarak, bir önceki adımda hesaplanan akışkan miktarları göz önüne alınarak, süreklilik denklemi ile her bir hücrenin hacimsel doluluk oranı belirlenir.

\section{5. Çözüm Bölgesinin Sınır Şartları}

Şekil 3, kritik-altı açık kanal akımının sayısal modeli için kullanılan çözüm bölgesi ve onun sınır şartlarını göstermektedir. $x, y$ koordinat sisteminin orijini, çözüm bölgesinin sol alt köşesinde alınmış, sınır şartları olarak çözüm bölgesinin üst ve çıkıș sınırlarında $p=0$, kanal tabanında sifir hız, yani $u=0, v=0$ olarak tanımlanmıştır. Giriş sınır şartı olarak yatay hız bileşeni iki ayrı deney durumunda $u=0,418 \mathrm{~m} / \mathrm{s}$ ve $0,226 \mathrm{~m} / \mathrm{s}$ olarak tanımlanırken düşey hız bileşeni $v=0$ olarak alınmıştır. 
Zamana bağlı çözüm sürecinde, başlangıç şartı olarak, $t=0$ anında boş olan çözüm bölgesinin giriş sınırında VOF yöntemi için $F=1$ alınmış ve sayısal modellemede kullanılan tüm türbülans modelleri için zaman adımı $\Delta t=0,001 \mathrm{~s}$ olarak seçilmiştir. Kanal tabanında katı sınıra yakın akım bölgesinin modellenmesinde Chen ve Patel [14] tarafindan önerilen iki-tabakalı çözümü esas alan ve genişletilmiş iki-tabakalı duvar-yakını modellemesi olarak anılan yöntem kullanılmıştır.

(1) ve (2) temel denklemlerinin, Şekil 3 'te görülen sınır şartlarına göre $\bar{u}, \bar{v}$ ve $\bar{p}$ için sayısal çözümü, sonlu hacimler yöntemine dayalı ANSYS-Fluent $^{\circledR} \quad$ v.12.1 paket programı kullanılarak yapılmıştır.

\subsection{Hesaplama Ăğının Tasarımı}

Hesaplama ağının tasarımı için çözüm bölgesi, Şekil 4'te görüldüğü gibi dört alt bölgeye ayrılmış ve ağ yapısının çözüm üzerindeki etkisinin incelenmesinde kullanılan ayrıklaştırma hatasının tespiti için üçlü bir hesaplama ağı oluşturulmuştur. Hesaplama ağının her bir alt bölgesindeki eleman sayısı yaklaşık olarak $\% 50$ ve $\% 100$ oranında artırılmak suretiyle dörtgen elemanlardan oluşan üç farkl1 yoğunluğa sahip, Ağ1-Kaba, Ağ2-Orta ve A ğ3-İnce, hesaplama ağları oluşturulmuştur. Çizelge 2'de, sayısal hesaplamalarda kullanılan üç farklı ağ yapısı için eleman sayıları verilmiştir. Sayısal çözüm alanındaki ă̆ yapısının yeterli sıklıkta olup olmadı̆̆ı, bir başka ifadeyle a $\breve{g}$ yapısından bağımsız sayısal çözümler elde etmek amacıyla ele alınan üçlü ağ sisteminde yapılan sıklaştırmanın uygunluğu, GCI (Grid Convergence Index-A $\breve{g}$ Yakınsama İndeksi) yöntemiyle test edilmiştir $[15,16]$. Beş farklı kesitte $(x=0,30 \mathrm{~m}$, $0,70 \mathrm{~m}, 1,10 \mathrm{~m}, 1,50 \mathrm{~m}$ ve $1,90 \mathrm{~m}$ ) yapılan ağ yakınsama indeksi değerlerinin A $\breve{g} 3$ itibariyle \% 0,023 ile \% 1.96 değerleri arasında değiştiği görülmüştür. Böylece, A $\breve{3} 3$ sistemiyle, akım hızlarındaki hataların kabul edilebilir bir sınır olan \% 2'den küçük olduğu görülmüş ve hesaplama hassasiyetinin ağ yoğunluğundan bağımsızlaştığ1 kanaatine varılmıştır.

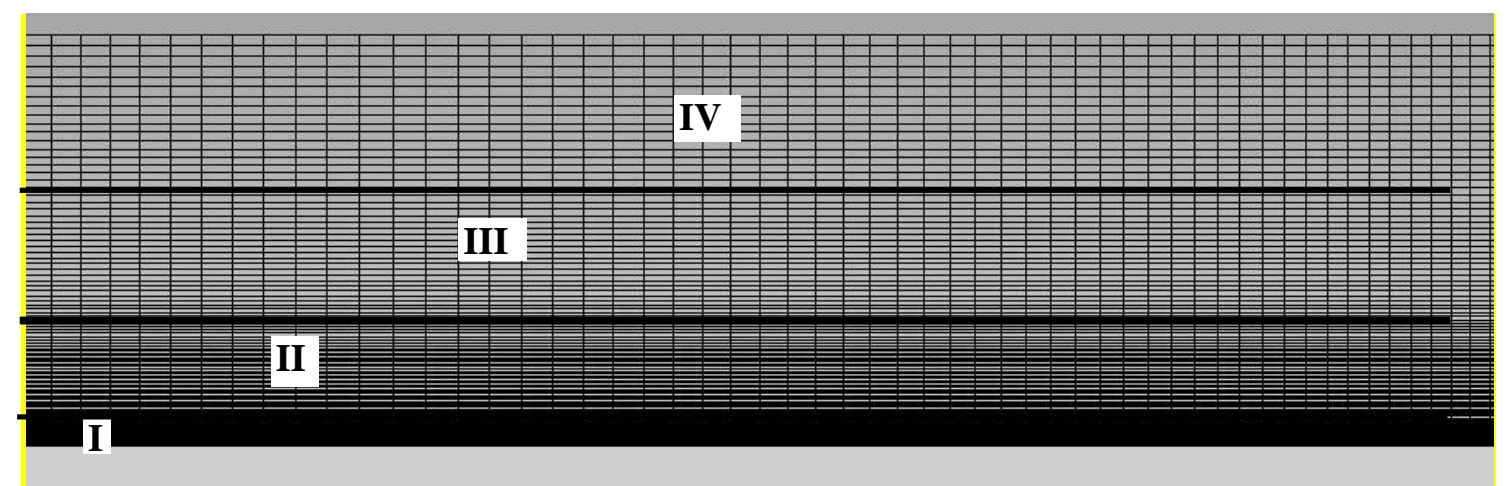

Şekil 4. Sayısal modelde kullanılan hesaplama ağı

Çizelge 2. Farklı yoğunluktaki hesaplama ağlarında bölgesel eleman sayıları

\begin{tabular}{|c|c|c|c|}
\hline Bölge No & Ăg1-Kaba & Ăg2-Orta & Ăg3-İnce \\
\hline $\mathbf{I}$ & $30 \times 250$ & $45 \times 375$ & $60 \times 500$ \\
\hline II & $8 \times 250$ & $12 \times 375$ & $15 \times 500$ \\
\hline III & $10 \times 250$ & $15 \times 375$ & $20 \times 500$ \\
\hline IV & $20 \times 250$ & $30 \times 375$ & $40 \times 500$ \\
\hline
\end{tabular}


Şekil 5'te, Deney 1 durumu için kanalın farklı kesitlerinde ölçülen yatay hız profilleri ve üç farklı türbülans modeli kullanılarak elde edilen sayısal bulgulara ait grafikler verilmiştir. Bu grafiklerde, $x=20,50,70,90,110$ ve $130 \mathrm{~cm}$ kesitlerinde üç modelin birbirine yakın sonuçlar verdiği görülmektedir. Ayrıca özellikle $x=70,90,110$ ve $130 \mathrm{~cm}$ kesitlerinde sayısal bulguların deneysel ölçümlere daha çok yaklaştığı görülmektedir. Kanalın sonuna doğru $x=150,190$ ve $210 \mathrm{~cm}$ kesitlerinde ise, türbülans modelleri ve deney bulguları birbirine oldukça yakın olup RKE ve RNG modellerinin katı sınıra yakın bölgelerde SKE modelinden daha başarılı olduğu görülmektedir.

Şekil 6'da, Deney 2 durumunda, kanalın farklı kesitlerinde ölçülen yatay hız profilleri ve üç farklı türbülans modeli kullanılarak elde edilen sayısal bulgulara ait grafikler verilmiştir. Şekilde görüldüğü gibi, daha düşük debiye sahip Deney 2 durumunda üç türbülans modeli de tüm kesitlerde farklı davranışlar sergilemektedir. $x=50,70,90$ ve $130 \mathrm{~cm}$ kesitlerinde, katı sınıra yakın bölgeyi modellemede RNG; katı sınırdan uzaklaşılan yerlerde ise RKE türbülans modeli deneysel bulgulara yaklaşmada diğerlerine göre daha başarılı olmuştur. $x=150, \quad 190$ ve $210 \mathrm{~cm}$ kesitlerinde, RKE modeli bulgularının tüm derinlik boyunca deneysel bulgularla gayet uyumlu olduğu görülmektedir.

Şekil 5 ve 6'daki deneysel ve hesaplanan hız profillerinin incelenmesinden; SKE türbülans modelinin kanal başındaki kesitlerde RNG ve RKE modellerininkine benzer sonuçlar verdiği, ancak akım geliştikçe başarı düzeyinin düştüğü görülmektedir. Genel olarak, her iki deney durumu için verilen hiz profillerinden, RKE modeli ile hesaplanan bulguların Çizelge 3 ve Çizelge 4 'de verilen $\mathrm{OKH}$ değerleriyle uyumlu bir şekilde deneysel bulgulara daha çok yaklaştı̆̆ görülmektedir.

\section{SONUÇ}

Yavaş değişen üniform-olmayan kritik-altı açık kanal akımın sayısal modellenmesinde akımı idare eden denklemler, sonlu hacimler yöntemine dayalı ANSYS-Fluent paket programı ile çözülmüştür. Sayısal hesaplamalarda SKE, RNG ve RKE türbülans modelleri kullanılmış, serbest su yüzünün profili VOF yöntemi ile belirlenmiştir. Hesaplama ağı yapısının, sayısal bulgular üzerindeki etkisini incelemek üzere, $\mathrm{Ağ}$ Yakınsama İndeksi (GCI) ölçüt olarak kullanılmış ve ağ yoğunluğuna bağlı hesaplama hatasının $\% 2$ 'nin altında kaldığı görülmüştür.

Sayısal modellemelerden hesaplanan hız profillerinin deneylerde ölçülenlerle karşılaştırılmasından, ele alınan üç türbülans modeli kullanılarak hesaplanan bulguların birbirlerine yakın olması nedeniyle her üç $k$ - $\varepsilon$ modelinin de, yani SKE, RNG ve RKE türbülans modellerinin, çalışmaya konu olan akım türünün sayısal çözümünde başarılı bir şekilde kullanılabileceği anlaşılmıştır. Bununla birlikte, RNG ve RKE türbülans modellerinin SKE modeline göre özellikle kanal sonuna doğru daha başarılı olduğu görülmüştür.

\section{KAYNAKLAR}

1. Aydın, M.C. 2012. CFD simulation of freesurface flow over triangular labyrinth side weir. Advances in Engineering Software. 45(1): 159166.

2. Haun, S., Olsen, N.R.B. ve Feurich, R. 2011. Numerical Modeling of Flow over Trapezoidal Broad-Crested Weir. Engineering Applications of Computational Fluid Mechanics. 5(3): 397405.

3. Kırkgöz, M.S., Aköz, M.S. ve Öner, A.A. 2008. Experimental and Theoretical Analyses of Two-Dimensional Flows Upstream of Broad-Crested Weirs. Canadian Journal of Civil Engineering. 35(9): 975-986.

4. Öner, A.A., Aköz, M.S., Kırkgoz, M.S. ve Gümüş, V. 2012. Experimental Validation of Volume of Fluid Method for a Sluice Gate Flow. Advances in Mechanical Engineering. 
Çizelge 3. Deney 1'de türbülans modelleri ile hesaplanan hız profilleri için OKH değerleri

\begin{tabular}{|c|c|c|c|}
\hline \multirow{2}{*}{$x(\mathbf{c m})$} & \multicolumn{3}{|c|}{ OKH $\left(\mathrm{cm}^{2} / \mathrm{s}^{2}\right)$} \\
\hline & SKE & RNG & RKE \\
\hline 10 & $1,5000^{(2)}$ & $2,8000^{(3)}$ & $0,9930^{(1)}$ \\
\hline 20 & $1,3000^{(3)}$ & $1,1000^{(2)}$ & $0,9890^{(1)}$ \\
\hline 35 & $0,8960^{(2)}$ & $0,9760^{(3)}$ & $0,7120^{(1)}$ \\
\hline 50 & $0,8430^{(2)}$ & $1,1000^{(3)}$ & $0,7110^{(1)}$ \\
\hline 70 & $0,3320^{(3)}$ & $\mathbf{0 , 2 4 3 0}^{(1)}$ & $0,2470^{(2)}$ \\
\hline 90 & $0,4200^{(3)}$ & $0,4010^{(2)}$ & $0,3740^{(1)}$ \\
\hline 110 & $0,5360^{(3)}$ & $0,5300^{(2)}$ & $0,4930^{(1)}$ \\
\hline 130 & $0,2680^{(2)}$ & $0,2820^{(3)}$ & $0,2520^{(1)}$ \\
\hline 150 & $0,3570^{(3)}$ & $\mathbf{0 , 3 0 3 0} 0^{(1)}$ & $0,3280^{(2)}$ \\
\hline 170 & $0,3980^{(3)}$ & $\mathbf{0 , 3 3 0 0} 0^{(1)}$ & $0,3760^{(2)}$ \\
\hline 190 & $0,3620^{(3)}$ & $\mathbf{0 , 2 2 7 0}^{(1)}$ & $0,2980^{(2)}$ \\
\hline 210 & $0,2390^{(3)}$ & $0,1960^{(1)}$ & $0,2350^{(2)}$ \\
\hline Ortalama & $0,6209^{(2)}$ & $0,7073^{(3)}$ & $0,5007^{(1)}$ \\
\hline
\end{tabular}

Çizelge 4. Deney 2'de türbülans modelleri ile hesaplanan hız profilleri için OKH değerleri

\begin{tabular}{|c|c|c|c|}
\hline \multirow{2}{*}{$\mathbf{s}(\mathbf{c m})$} & \multicolumn{3}{|c|}{ OKH $\left(\mathrm{cm}^{2} / \mathrm{s}^{2}\right)$} \\
\hline & SKE & RNG & RKE \\
\hline 10 & $0,2930^{(3)}$ & $0,1680^{(1)}$ & $0,2330^{(2)}$ \\
\hline 20 & $0,2650^{(3)}$ & $0,1420^{(1)}$ & $0,1590^{(2)}$ \\
\hline 35 & $0,1590^{(3)}$ & $0,1250^{(2)}$ & $0,0964^{(1)}$ \\
\hline 50 & $0,0839^{(3)}$ & $0,0609^{(2)}$ & $0,0486^{(1)}$ \\
\hline 70 & $0,0945^{(3)}$ & $0,0866^{(2)}$ & $\mathbf{0 , 0 5 9 8}^{(1)}$ \\
\hline 90 & $0,1410^{(3)}$ & $0,0350^{(1)}$ & $0,0628^{(2)}$ \\
\hline 110 & $0,1169^{(3)}$ & $0,1160^{(2)}$ & $0,0544^{(1)}$ \\
\hline 130 & $0,2490^{(3)}$ & $0,1010^{(1)}$ & $0,1070^{(2)}$ \\
\hline 150 & $0,1340^{(3)}$ & $0,1299^{(2)}$ & $\mathbf{0 , 0 4 8 8}^{(1)}$ \\
\hline 170 & $0,1686^{(3)}$ & $0,1254^{(2)}$ & $0,0565^{(1)}$ \\
\hline 190 & $0,0974^{(2)}$ & $0,1520^{(3)}$ & $0,0463^{(1)}$ \\
\hline 210 & $0,0799^{(2)}$ & $0,1660^{(3)}$ & $\mathbf{0 , 0 3 1 9} 9^{(1)}$ \\
\hline Ortalama & $0,1569^{(3)}$ & $0,1173^{(2)}$ & $0,0837^{(1)}$ \\
\hline
\end{tabular}



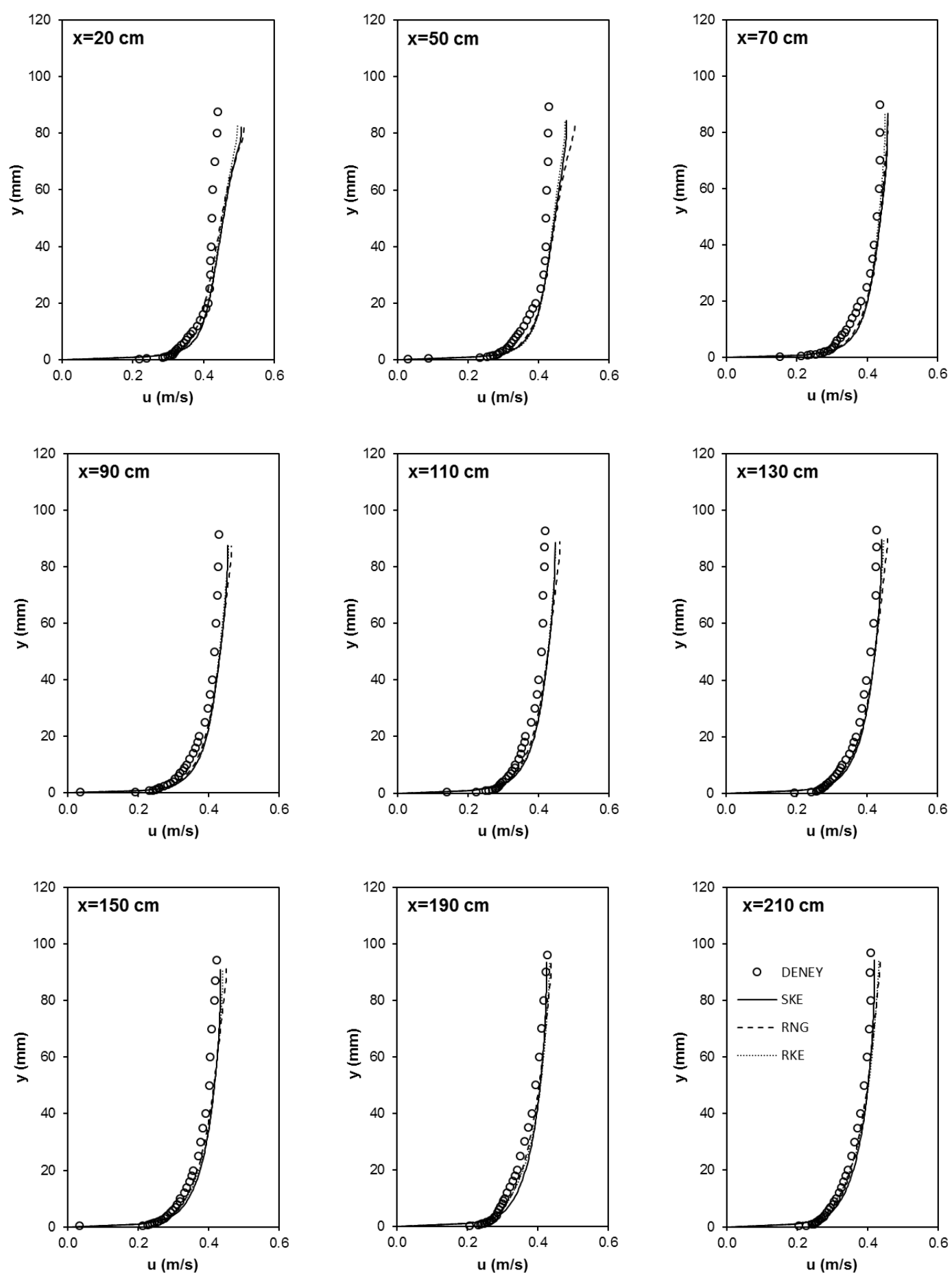

Şekil 5. Deney 1 için kanal boyunca farklı kesitlerde deneysel ve hesaplanan hız profilleri 

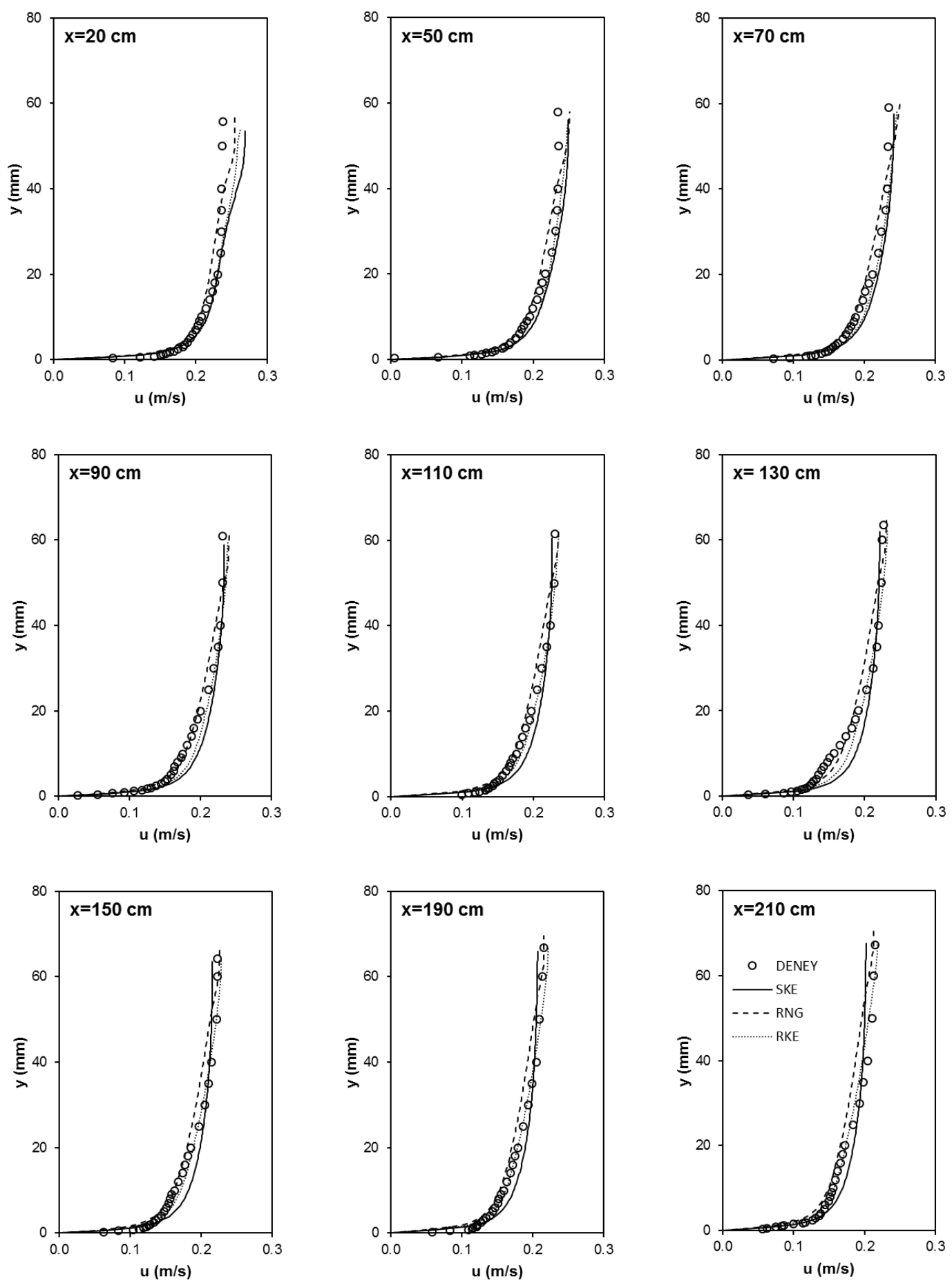

Şekil 6. Deney 2 için kanal boyunca farklı kesitlerde deneysel ve hesaplanan hız profilleri 
6. Gümüş, V., Aköz, M.S. ve Kırkgöz, M.S. 2013. Experimental and Numerical Modeling of Submerged Hydraulic Jump Downstream of a Sluice Gate. TEKNIK DERGI. 24(2): 63796397.

7. Kırkgoz, M.S., Aköz, M.S. ve Öner, A.A. 2008. Experimental and Theoretical Analyses of Two-Dimensional Flows Upstream of Broad-Crested Weirs. Canadian Journal of Civil Engineering. 35(9): 975-986.

8. Kırkgöz, M.S., Aköz, M.S. ve Öner, A.A. 2009. Numerical Modeling of Flow Over a Chute Spillway. Journal of Hydraulic Research. 47(6): 790-797.

9. Launder, B.E. ve Spalding, D.B. 1972. Lectures in Mathematical Models of Turbulence. New York: Academic Press.

10. Yakhot, V., Orszag, S.A., Thangam, S., Gatski, T.B. ve Speziale, C.G. 1992. Development of Turbulence Models for Shear Flows by a Double Expansion Technique. Physics of Fluids a-Fluid Dynamics. 4(7): 1510-1520.

11. Shih, T.-H., Liou, W.W., Shabbir, A., Yang, Z. ve Zhu, J. 1995. A new k-€ Eddy Viscosity Model For High Reynolds Number Turbulent Flows. Computers \& Fluids. 24(3): 227-238.

12. Hirt, C.W. ve Nichols, B.D. 1981. Volume of Fluid (VOF) Method for the Dynamics of Free Boundaries. Journal of Computational Physics. 39(1): 201-225.

13. ANSYS. 2012. FLUENT Theory Guide. USA: ANSYS Inc.

14. Chen, H.C. ve Patel, V.C. 1988. Near-Wall Turbulence Models for Complex Flows Including Separation. Aiaa Journal. 26(6): 641648.

15. Roache, P.J. 1998. Verification of Codes and Calculations. Aiaa Journal. 36(5): 696-702.

16. Celik, I.B., Ghia, U., Roache, P.J. ve Freitas, C.J. 2008. Procedure for Estimation and Reporting of Uncertainty Due to Discretization In CFD Applications. Journal of Fluids Engineering-Transactions of the Asme. 130(7). 
